\title{
Perencanaan dan Analisa Perhitungan Jumlah Tube dan Diameter Shell pada Kondensor Berpendingin Air pada Sistem Refrigerasi $\mathrm{NH}_{3}$
}

\author{
Design and Calculation Analysis for the Number of Tubes and Shell Diameter on Water- \\ cooled Condenser of NH3 Refrigeration System
}

\author{
Sobar Ihsan \\ Universitas Islam Kalimantan MAB \\ Fakultas Teknik \\ Banjarmasin, Indonesia \\ sobar.uniska@gmail.com
}

\begin{abstract}
Abstrak- Jenis penukar kalor sangatlah beragam dan masing masing dirancang untuk memenuhi kebutuhan yang spesifik. Namun demikian jenis shell \& tube sejauh ini merupakan jenis yang paling banyak dipergunakan berkat konstruksinya relatif sederhana dan memiliki keandalan karena dapat dioperasikan dengan beberapa jenis fluida kerja. Efek pendinginan yang dihasilkan dalam sistem refrigerasi tergantung dari efektivitas kinerja kondensor. Sementara, kinerja kondensor semakin lama akan menurun seiring dengan terjadinya fouling factor. Pada penelitian ini dilakukananalisaperhitunganjumlah tube dan diameter shell padakondensor sebagai Alat Penukar Kalor (APK). Dari hasil analisaperhitunganadalah diameter shell $720 \mathrm{~mm}$, jumlah tube 192 buah, diameter tube $38.1 \mathrm{~mm}$, panjang tube $3 \mathrm{~m}$, beda temperatur rata-rata LMTD 8.86 K.Dalam penentuan parameter temperatur desain kondensor sistem cooling-tower, harus mempertimbangkan kinerja cooling-tower dan perubahan temperatur udara.
\end{abstract}

Kata kunci: kondensor, optimal, shell and tube

Abstract-Heat Exchanger tools may vary from one another, Each of them is designed for specific uses. However, among all of these variants, shell and tube ar the most common in usage, in construction, and it has advantage that it can be used with different (several) kind of working fluid. The cooling effect that is produced by the refrigeration system depends on the performance effectivity of condenser. Meanwhile condencer performance will gradually decrease as the occurrence of fouling factor. In this research, There will be an optimal analysis of shell and tube thermal system as a Heat Exchanger. The optimum result is with shell's diameter is $720 \mathrm{~mm}$, and the total amount of tube is 192 tubes, with the diameter is $38.1 \mathrm{~mm}$, length is $3 \mathrm{~m}$, The average temperature difference LMTD $8.86 \mathrm{~K}$ and with the overall Heat Exchanger coefficient is $U 1448.21 \mathrm{~W} / \mathrm{m}^{2} \mathrm{~K}$. In giving the temperature parameter into the design of coolingtower condenser system, it need to consider about the coolingtower performance and the changing temperature of air.

Key words: condenser, optimal, shell and tube

\section{PENDAHULUAN}

Kondensor merupakan komponen pendingin yang sangat penting yang berfungsi untuk memaksimalkan efisiensi pada mesin pendingin.

Pada kondensor ini, terjadi pelepasan kalor secara kondensasi dan kalor sensibel. Pada umumnya menggunakan kondensor tipe permukaan (surface condenser), tipe kondensor ini merupakan jenis shell-tube yang mana air pendingin disirkulasikanmelalui tube.

Kondensorbiasanya menggunakan sirkulasi air pendingin dari menara pendingin (cooling tower) untuk melepaskan kalor ke atmosfir, atau once-through water dari sungai, danau atau laut.

Kebanyakan aliran fluida kerja yang mengalir secara terus menerus di dalam alat penukar kalor (APK), setelah melampaui waktu operasi tertentu akan mengotori permukaan perpindahan panasnya. Deposit yang terbentuk di permukaan kebanyakan akan mempunyai konduktivitas termal yang cukup rendah sehingga akan mengakibatkan menurunnya besaran koefisien global perpindahan panas di dalam alat penukar kalor, akibatnya laju pertukaran energi panas di dalam APK menjadi lebih rendah.

Untuk memperoleh performan yang sebaik-baiknya maka alat penukar kalor harus dirancang dengan cara yang seksama dan seoptimal mungkin. Oleh karena itu penguasaan metode perancangan sebuah alat penukar kalor menjadi sangat penting karena akan memberikan kontribusi yang sangat besar kepada upaya peningkatan performance instalasi industri, yang berarti juga kepada upaya penghematan energi terutama di sektor industri.

Dari penelitian ini diharapkan mampu melakukan perancangan sebuah alat penukar kalor (APK) sesuai dengan standar yang berlaku sehingga dapat dihasilkan alat penukar kalor (APK) yang memiliki efektifitas yang tinggi.

Tujuan dari penelitian ini adalah : 
- Mempelajari Seberapa besar pengaruh faktor ukuran tube, jarak antar tube, dan bentuk susunan tube terhadap kondesor.

- Mengidentifikasi kondisi design paling ekonomis.

\section{BAHAN DAN METODE}

Dalam melaksanakan penelitian ini digunakan suatu metode dan prosedur penelitian, sehingga langkah-langkah serta tujuan dari penelitian yang dilakukan dapat sesuai dengan apa yang diharapkan.

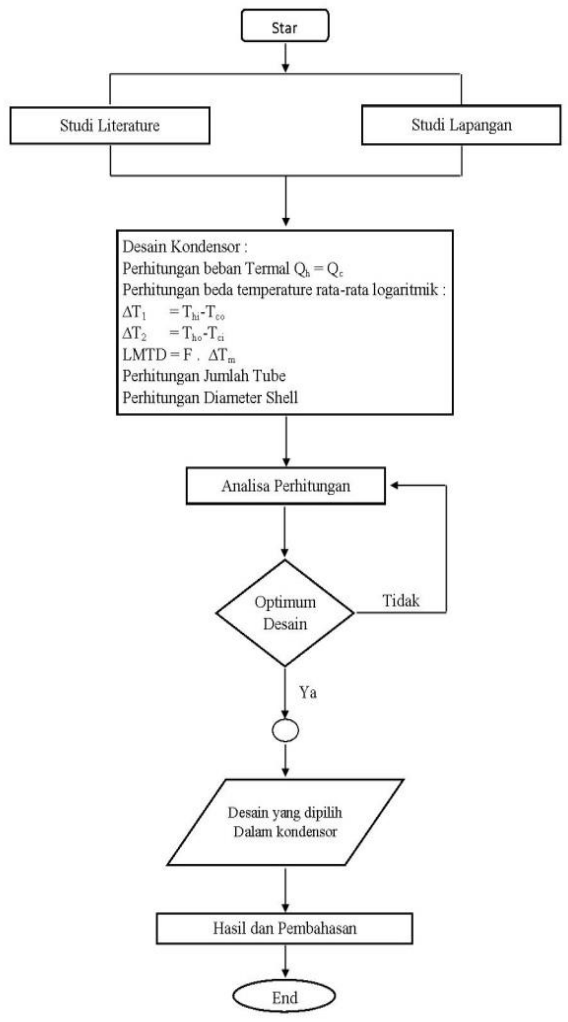

Gambar 1. Alur Penelitian

\section{Data Spesifikasi alat penukar kalor}

Sebagai bahan obyek penelitian adalah sebuah alat penukar kalor tipe shell and tube pada mesin pendingin dengan spesifikasi teknis yang didapat sebagai berikut :

- Refrigerant

: Amoniak $\left(\mathrm{NH}_{3}\right)$

- Tipe Kompresor : : Sentrifugal

- Kondensor : : Berpendingin air

- Tipe kondensor : Shell and tube

- Aliran fluida : Cross-flow. Air pendingin pada sisi tube dan $\mathrm{NH}_{3}$ pada sisi shell.

\section{HASIL DAN PEMBAHASAN}

Berdasarkan analisis data dan pengukuran data awal kondisi operasi yang diberikan untuk alat penukar kalor kondensor tipe shell dan tube sebagai berikut:

1. Tekanan masuk $20.2 \mathrm{kpa}$

2. Tekanan keluar $202 \mathrm{kpa}$

3. Temperatur air masuk $\left(T_{c i}\right) 26{ }^{\circ} \mathrm{C}$,
4. Temperatur air keluar $\left(T_{c o}\right) 55^{\circ} \mathrm{C}$,

5. Temperatur gas $\mathrm{NH}_{3}\left(T_{h i}\right) 77^{\circ} \mathrm{C}$,

6. Temperatur gas $\mathrm{NH}_{3}\left(T_{h o}\right) 35^{\circ} \mathrm{C}$,

7. Laju aliran massa $14.82 \mathrm{~kg} / \mathrm{s}$

Perhitungan perpindahan kalor yang diterima oleh aliran fluida air

Besarnya laju aliran fluida air yang ada di kondensor dapat dihitung dengan menggunakan persamaan dibawah ini:

$Q_{c}=m_{c} \cdot c_{p c}\left(T_{c o}-T_{c i}\right)$

Dan dari persamaan kesetimbangan energy, maka kalor yang diterima air dianggap sama dengan kalor yang dilepas gas $\mathrm{NH}_{3}$. Sehingga $Q_{c}=Q_{h}$ merupakan nilai perpindahan kalor aktual yang dilepaskan pada alat penukar kalor.

Dimana :

$$
\begin{array}{ll}
m_{c} & =14.82 \mathrm{~kg} / \mathrm{s} \\
T_{c o} & =55^{\circ} \mathrm{C}=328 \mathrm{~K} \\
T_{c i} & =26{ }^{\circ} \mathrm{C}=299 \mathrm{~K}
\end{array}
$$

Kemudian, Sifat-sifat fisik fluida air (lihat tabel sifat-sifat fisik fluida air), yang dievaluasi pada temperatur $55{ }^{\circ} \mathrm{C}$ memberikan data :

$\rho=988 \mathrm{~kg} / \mathrm{m}^{3}$

$\mathrm{c}_{\mathrm{pc}}=4181 \mathrm{~J} / \mathrm{kgK}$

$\mu=548 \cdot 10^{-6} \mathrm{Ns} / \mathrm{m}^{2}$

$\mathrm{k}=0.643 \mathrm{~W} / \mathrm{mK}$

$\operatorname{Pr}=3.56$

Maka diperoleh,

$$
\begin{gathered}
\mathrm{Q}_{\mathrm{c}}=14.82 \mathrm{~kg} / \mathrm{s} \times 4181 \mathrm{~J} / \mathrm{kg} . \mathrm{Kx}(328-299) \\
=1796910.18 \mathrm{~W}=1796.91 \mathrm{~kW}
\end{gathered}
$$

\section{Perhitungan perpindahan kalor yang dilepas gas $\mathrm{NH}_{3}$}

Sistem pendinginan yang dilakukan pada mesin pendingin dimana menggunakan fluida pendinginnya yaitu gas $\mathrm{NH}_{3}$ dan air. Laju aliran massa fluida pendingin pada kondensor yaitu $14.82 \mathrm{~kg} / \mathrm{s}$.

Selanjutnya untuk menentukan besarnya laju perpindahan kalor yang dilepas gas $\mathrm{NH}_{3}$ pada alat penukar kalor dapat dihitung dengan menggunakan persamaan berikut ini:

$Q_{h}=m_{h} \cdot c_{p h}\left(T_{h i}-T_{h o}\right)$

Kemudian, Dari data sifat-sifat fisik ammoniak $\mathrm{NH}_{3}$ (tabel sifat-sifat fluida ammoniak) yang dievaluasi pada temperatur $77{ }^{\circ} \mathrm{C}$ diperoleh harga $\mathrm{c}_{\mathrm{ph}}=2550 \mathrm{~J} / \mathrm{kgK}$. Sehingga:

$m_{h}=\frac{Q_{h}}{c_{p h \cdot\left(T_{h i}-T_{h o}\right)}}$

Dimana

$Q_{c} \quad=Q_{h} \quad=179.61 \mathrm{~kW}$

$T_{h i} \quad=77^{\circ} \mathrm{C}=350 \mathrm{~K}$ 


$$
\begin{array}{ll}
T_{h o} & =35^{\circ} \mathrm{C}=308 \mathrm{~K} \\
c_{p} & =2550 \mathrm{~J} / \mathrm{kg} \mathrm{K}
\end{array}
$$

Maka diperoleh,

$$
\begin{array}{r}
m_{h}=\frac{179691}{2550 \mathrm{~kJ} / \mathrm{kg} \cdot K(350-308)} \\
=\frac{179691}{107100}=1.68 \mathrm{~kg} / \mathrm{s}
\end{array}
$$

$Q_{h}$ merupakan laju aliran perpindahan kalor yang dilepas gas $\mathrm{NH}_{3}$ dan merupakan energi yang dikeluarkan oleh alat penukar kalor $\left(Q_{o u t}\right)$.

\section{Perhitungan Beda Temperatur Rata-rata Logaritmik,}

\section{LMTD}

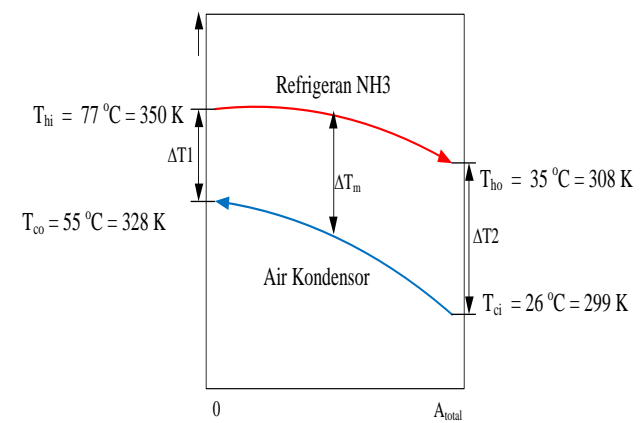

Gambar 2. Distribusi temperatur $\mathrm{NH}_{3}$ dan air pada kondensor

Besarnya harga beda temperatur $\Delta T_{1}$ yang dievaluasi dengan persamaan berikut ini:

$\Delta T_{l}=T_{h i}-T_{c o}$

Dimana,

$T_{h i}=77{ }^{\circ} \mathrm{C}=350 \mathrm{~K}$

$T_{c o}=55^{\circ} \mathrm{C}=328 \mathrm{~K}$

Maka diperoleh,

$\Delta T_{1}=350 \mathrm{~K}-328 \mathrm{~K}$

$\Delta T_{1}=22 \mathrm{~K}$

Besarnya harga beda temperatur $\Delta T_{2}$ yang dievaluasi dengan persamaan dibawah ini:

$\Delta T_{2}=T_{h o}-T_{c i}$

Dimana,

$T_{h o}=35^{\circ} \mathrm{C} \quad=308 \mathrm{~K}$

$T_{c i}=26^{\circ} \mathrm{C} \quad=299 \mathrm{~K}$

Maka diperoleh,

$\Delta T_{2}=308 \mathrm{~K}-299 \mathrm{~K}$

$\Delta T_{2}=9 \mathrm{~K}$

Besarnya nilai beda temperatur rata-rata logaritmik, $\Delta T_{m}$ dapat dievaluasi dengan menggunakan persamaan berikut:

$\Delta T_{m}=\frac{\Delta T_{1}-\Delta T_{2}}{\ln \left\lfloor\frac{\Delta T_{1}}{\Delta T_{2}}\right\rfloor}$

Dimana,

$\Delta T_{1}=22 \mathrm{~K}$

$\Delta T_{2}=9 \mathrm{~K}$
Maka diperoleh,

$$
\begin{aligned}
\Delta T_{m} & =\frac{22-9}{\ln \left\lfloor\frac{22}{9}\right\rfloor} \\
& =9.84 \mathrm{~K}
\end{aligned}
$$

Faktor untuk koreksi konfigurasi shell\&tube

Faktor koreksinya dapat ditentukan dengan menggunakan data yang sesuai dengan harga-harga parameter $\mathrm{P}$ dan $\mathrm{R}$ sebagai berikut:

$$
\begin{aligned}
& \mathrm{P}=\frac{328-299}{308-299}=0.32 \\
& \mathrm{R}=\frac{350-308}{328-299}=0.29
\end{aligned}
$$

Dari data grafik faktor koreksi untuk shell \& tube, diperoleh:

$$
\begin{aligned}
& F_{c}=\frac{\sqrt{\left(0.29^{2}+1\right)} \cdot\{0.32+1\}}{(0.29+1) \ln \frac{0.32}{0.29}} \\
& =0.87
\end{aligned}
$$

LMTD dapat diperoleh dengan menggunakan persamaan dibawah ini:

$L M T D=F_{c} . \Delta T_{m}$

dimana :

$F_{c} \quad=0.9$

$\Delta T_{m} \quad=9.84 \mathrm{~K}$

Maka diperoleh:

$$
L M T D=0.9 .(9.84 \mathrm{~K})=8.86 \mathrm{~K}
$$

Perhitungan luas permukaan perpindahan panas total, Atotal

Besarnya $\mathrm{Q}_{\mathrm{o}}$ dapat dianggap sama dengan $\mathrm{Q}=\mathrm{Q}_{\mathrm{h}}=\mathrm{Q}_{\mathrm{o}}=$ $179691 \mathrm{~W}$

$$
\begin{aligned}
A_{o} & =\pi d_{o} L N_{t} \\
& =3.14 \times 0.0381 \times 3 \times 192 \\
& =68.9 \mathrm{~m}^{2}
\end{aligned}
$$

\section{Perhitungan diameter shell (Ds)}

Diameter shell, dapat dihitung menggunakan persamaan berikut:

$D_{s}=0.637\left(\frac{C l}{C T_{p}}\right)^{0.5}\left(\frac{A(P R)^{2} d_{o}}{L}\right)^{0.5}$

Dimana :

a. Diameter tube, $d_{o}=38.1 \mathrm{~mm}$

b. Panjang tube, $L=3 \mathrm{~m}$

c. Tube layout $30^{\circ}$, yg berarti $C L=0.87$

d. Aliran fluida di dalam tube: 1 pass yg berarti $C T_{p}=0.93$

e. Pitch ratio (jarak antar tube / diameter tube) $=1.25$

f. luas permukaan perpindahan panas $A_{o}=68.9 \mathrm{~m}^{2}$ Maka dengan mensubtitusi harga-harga diatas kedalam persamaan untuk diameter shell, akan diperoleh: 


$$
D_{s}=0.637\left(\frac{0.87}{0.93}\right)^{0.5}\left(\frac{68.9 x(1.25)^{2} \times 38.1}{3000}\right)^{0.5}
$$

$=0.637 \times 0.967 \times 1.16$

$=720 \mathrm{~mm}$

\section{Perhitungan diameter jumlah tube (Nt)} berikut:

Jumlah tube, dapat dihitung menggunakan persamaan

$$
N_{t}=0.785\left(\frac{C T_{p}}{C l}\right) \frac{D_{S}^{2}}{(P R)^{2}\left(d_{o}\right)^{2}}
$$

Dimana :

a. Diameter shell, $D_{s}=720 \mathrm{~mm}$

b. Diameter tube, $d_{o}=38.1 \mathrm{~mm}$

c. Tube layout $30^{\circ}$, yg berarti $C L=0.87$

d. Aliran fluida di dalam tube: 1 pass yg berarti $C T P=0.93$

e. Pitch ratio (jarak antar tube / diameter tube) $=1.25$

Maka diperoleh :

$$
\begin{aligned}
& N_{t}=0.785\left(\frac{0.93}{0.87}\right) \frac{720^{2}}{(1.25)^{2}(38.1)^{2}} \\
& \quad=0.785 \times 1.07 \times \frac{518400}{1.5625 \times 1451.61} \\
& =0.785 \times 1.07 \times 228.56 \\
& =192 \text { buah }
\end{aligned}
$$

Dari hasil perhitungan desain tersebut didapat diameter shell, $D s=720 \mathrm{~mm}$ dan jumlah tube, $N_{t}=192$ buah.

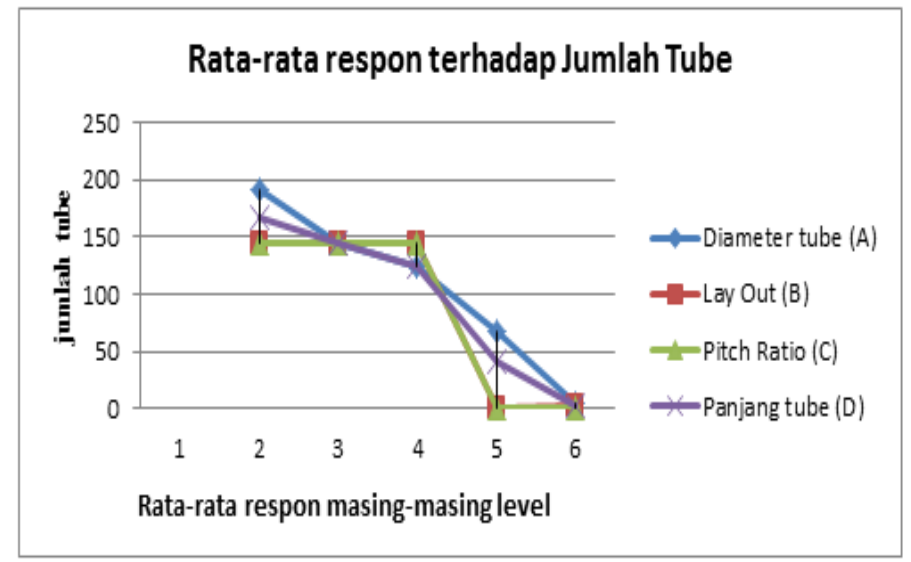

Gambar 3. Grafik pengaruh rata-rata respon masing-masing level terhadap jumlah tube

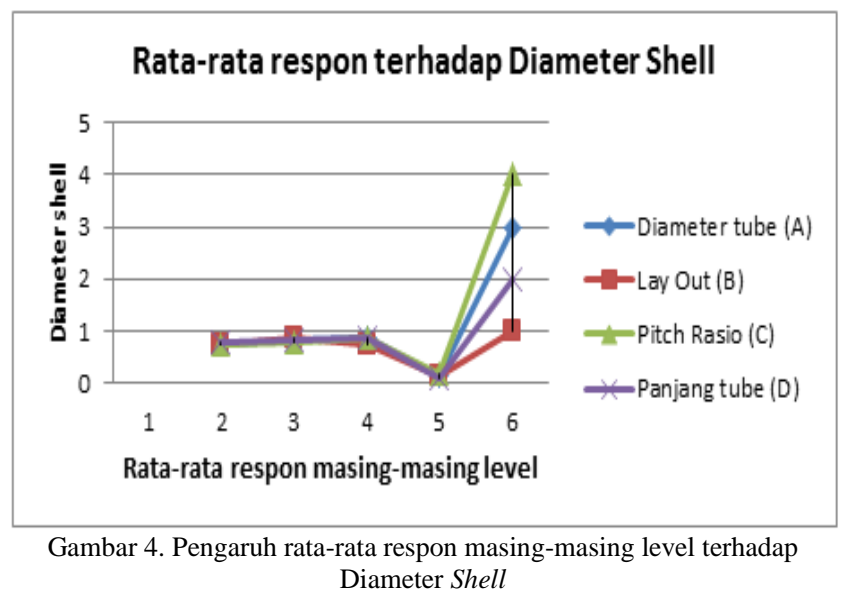

\section{KESIMPULAN}

Berdasarkan analisis data dan pembahasan, dapat diambil kesimpulan mengenai analisaperhitunganjumlah tube dan diameter shell kondensor pada mesin pendingin sebagai berikut :

1. Dari data awal spesifikasi alat penukar kalor kondensor tipe shell and tube setelah dilakukan perhitungan maka didapat diameter shell $720 \mathrm{~mm}$, panjang tube $3 \mathrm{~m}$, diameter tube $38.1 \mathrm{~mm}$, dan jumlah tube 192 buah.

2. Pengaruh rata-rata masing-masing faktor terhadap jumlah tube

a) Ukuran tube diameter $38.1 \mathrm{~mm}$, memberikan pengaruh yang lebih baik memberikan perpindahan panas yang besar dengan nilai koefesien perpindahan U sebesar $1448.21 \mathrm{~W} / \mathrm{m}^{2} \mathrm{~K}$

b) Sedangkan pada Panjang tube $3 \mathrm{~m}$ memberikan pengaruh yang lebih baik dari pada kedua Panjang tube yang lainnya

3. Pengaruh rata-rata masing-masing faktor terhadap diameter shell

a) Ukuran tube diameter $38.1 \mathrm{~mm}$, memberikan pengaruh yang lebih baik di mana memberikan hasil desain dengan dimensi yang paling ekonomis yaitu diameter shell yang terkecil yaitu $720 \mathrm{~mm}$.

b) Susunan antar tube (layout) $30^{\circ}$ dan $60^{\circ}$ (konstanta 0.87 ), memberikan pengaruh yang lebih baik.

c) Jarak antar tube (Pitch rasio) 1.25

\section{UCAPAN TERIMA KASIH}

Pada kesempatan ini, saya mengucapkan terima kasih yang tak terhingga kepada:

1. Bapak Dr. Mustatul Anwar, M.M.Pd., M.Kes selaku Rektor Universitas Islam Kalimantan MAB.

2. Bapak Budi Hartadi, ST., MT selaku Dekan Fakultas Teknik, Universitas Islam Kalimantan MAB.

3. Bapak Gusti Rusydi Furqon Syahrillah, ST., MT selaku Ketua Program Studi Teknik Mesin, Universitas Islam Kalimantan MAB.

4. Kedua orang tua saya, yang telah memberikan energi yang sangat laur biasa. 
5. Rekan-rekan PT. Wirontono Baru cab. Banjarmasin, yang telah memberi saya banyak informasi yang berguna dan bermanfaat dalam penelitian ini.

\section{DAFTAR PUSTAKA}

[1] Jurnal Al ulum Sains dan Teknologi. Jainal Arifin, Optimasi Shell and Tube Kondensor dan Pemanfaatan Energi Panas Terbuang Pada AC untuk Pemanas air. Vol 1, No 1, November 2015

[2] Jurnal Ilmu dan Aplikasi Teknik, Marno, Awal Nurahmadi, Kajian Alat Penukar Kalor Shell And Tube Menggunakan Program Heat Transfer Research Inc (HTRI). Volume 2 No.1, Januari 2017

[3] Jurnal Kajian Teknik Mesin. Audri Deacy Cappenberg. Analisa Kinerja Alat Penukar Kalor Jenis Pipa Ganda. Vol. 1 No. 2.

[4] Artikel Teknik Mesin. Sugiyanto. Analisis Alat Penukar Kalor Tipe Shell And Tube Dan Aplikasi Perhitungan Dengan Microsoft Visual Basic 6.0. Universitas Gunadarma. Depok.

[5] Artikel Teknik Fisika. M. Fahmi Rizal, Gunawan N, Ir. Sarwono. Rancang Bangun Perangkat Lunak untuk Desain Alat Penukar Panas Tipe Shell dan Tube. ITS. Surabaya.

[6] Kreith,Frank.1986.Prinsip-prinsip PerpindahanPanas.EdisiKetiga.Erlangga: Jakarta.

[7] Sitompul,TunggalM.1993.AlatPenukarKalor.Raja GrafindoPersada.

[8] Frank M. White. 1996. Mekanika Fluida Edisi kedua jilid 1. Jakarta : Erlangga.

[9] Proceeding SNTTM XIV. Putu Wijaya Sunu, Daud Simon Anakottapary dan Wayan G. Santika. Efektifitas Perpindahan Panas Pada Double Pipe Heat Exchanger Dengan Groove. Oktober 2015

[10]Dini Yuni Arifianto. 2009. RancangBangunDanPengujianModel KondensorTipe ConcentricTube CounterCurrentGanda DenganPenambahan sinip.UMSSurakarta.

[11] Muhammad Awwaluddin. 2007. Analisis Perpindahan Kalor Pada Heat Exchanger Pipa Ganda Dengan Sirip Berbentuk Delta Wing. UMS Semarang.

[12]Resman Tua Simarmata.2009. Analisis Perpindahan Kalor Pada Penukar Kalor Pipa Ganda Dengan Sirip Berbentuk Sayap Delta. UMB. Jakarta 